\title{
Primary thoracic extraskeletal osteosarcoma: a case report and literature review
}

\author{
Jie Qian ${ }^{1}$, Xue-Yan Zhang ${ }^{1}$, Ping Gu ${ }^{1}$, Jin-Chen Shao ${ }^{2}$, Bao-Hui Han ${ }^{1}$, Hui-Min Wang ${ }^{1}$ \\ ${ }^{1}$ Department of Pulmonary Medicine, ${ }^{2}$ Department of Pathology, Shanghai Chest Hospital, Shanghai Jiao Tong University, Shanghai 200240, China \\ Correspondence to: Hui-Min Wang, MD. Department of Pulmonary Medicine, Shanghai Chest Hospital, Shanghai Jiao Tong University, 241 West \\ Huaihai Road, Shanghai 200240, China. Email: whmxkyy@126.com; Bao-Hui Han, MD, PhD. Department of Pulmonary Medicine, Shanghai Chest \\ Hospital, Shanghai Jiao Tong University, 241 West Huaihai Road, Shanghai 200240, China. Email: xkyyhan@gmail.com.
}

\begin{abstract}
Primary extraskeletal osteosarcoma (ESOS) presenting in thoracic locations is very rare and associated with a poor prognosis. The current study presents a case involving a large anterior mediastinal mass, which was histologically confirmed as a primary osteosarcoma. The literature concerning primary thoracic ESOS is reviewed. A total of 60 cases were identified. The median age was 60 years (range, 14-93 years) and males were more prevalent among the reported cases (65\%). Survival analysis revealed that the overall 5 -year survival was only $22.3 \%$. The majority of cases of thoracic ESOS presented in the lung ( $\mathrm{n}=24,40 \%$ ), with others presenting in the mediastinum, pleura, or chest wall. The benefit of surgery, chemotherapy and radiotherapy was confirmed by Cox regression survival analyses.
\end{abstract}

Keywords: Extraskeletal osteosarcoma; thoracic; literature review

Submitted Jul 25, 2017. Accepted for publication Nov 08, 2017.

doi: $10.21037 /$ jtd.2017.11.111

View this article at: http://dx.doi.org/10.21037/jtd.2017.11.111

\section{Introduction}

Extraskeletal osteosarcoma (ESOS) is a malignant neoplasm producing osteoid in places other than bones or periosteum (1). Primary ESOS presenting in thoracic locations is very rare and associated with a poor prognosis. However, previously reported sporadic cases of primary thoracic ESOS did not provide a comprehensive profile of clinical manifestations. The optimal treatment of thoracic ESOS is largely unknown. Here we presented a case of primary ESOS located in the mediastinum. We discuss the clinico-characteristics with a review of the related literature.

\section{Case presentation}

A 55-year-old woman with a 3-month history of a palpable neck mass, progressive dyspnea and weight loss was admitted. She had a history of aluminum dust exposure and type 2 diabetes, but otherwise had no other major medical problems. Her general status was poor and a physical examination was unremarkable except for a palpable lymphadenopathy in the supraclavicular fossa. The blood biochemistry tests on admission showed largely normal results. A routine blood test, liver and kidney function tests, and levels of C-reactive protein, alkaline phosphatase and blood calcium were all normal. The tumor markers CEA, CYFRA21-1, SCC-Ag, NSE, and CA125 were within the normal range.

Contrast-enhanced computed tomography (CT) of the chest detected a $9.0 \mathrm{~cm} \times 6.4 \mathrm{~cm}$ soft-tissue mass with irregular contours in the anterior mediastinum. The trachea was significantly compressed and the relationship between the mass and the adjacent vessels was unclear. A quasicircular calcification was visualized in the mass (regional SUV $63 \mathrm{HU}$ ). The enlarged mediastinal lymph nodes had merged with the mass (Figure 1).

Fine-needle aspiration cytology of the supraclavicular lymph node showed interstitial fibrosis with diffused malignant small round cell involvement. An immunohistochemistry analysis did not provide clues of where the tumor originated. A whole-body PET/CT did not suggest another primary site either. 

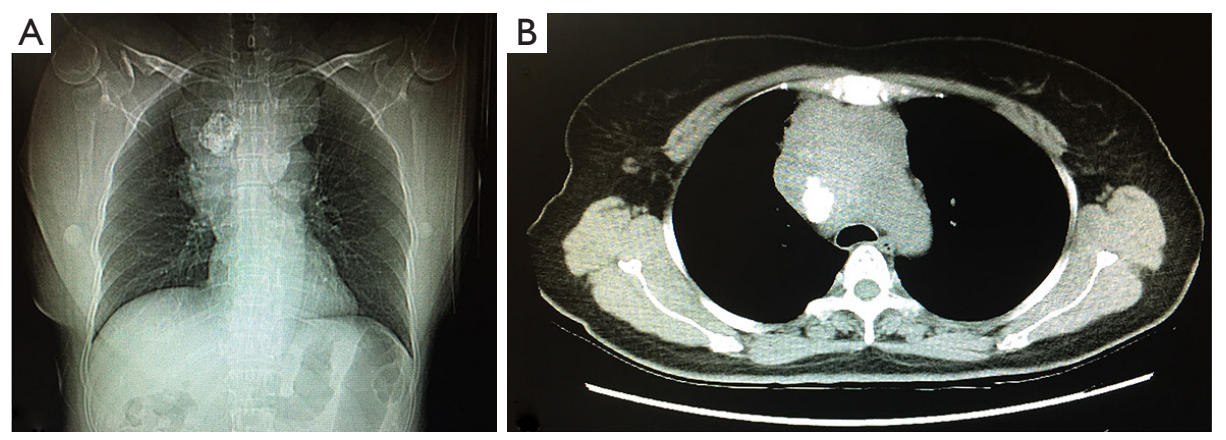

Figure 1 Computed tomogram of the lung showed an irregular mass $(9.0 \mathrm{~cm} \times 6.4 \mathrm{~cm})$ with accompanying calcification or ossification in the anterior mediastinum.

The tumor was surgically resected through a median sternotomy. Intraoperative findings revealed that the tumor was hard and protruded into bilateral anonymous veins, the superior vena cava, diaphragm and vagus nerve. Prosthetic replacement of the superior vena cava was performed. The right upper lobe was involved and a wedge resection was performed.

Histologically, the tumor was $11 \mathrm{~cm} \times 10 \mathrm{~cm} \times 10 \mathrm{~cm}$ in size without a complete capsule. The cut surface was grayish yellow and necrosis was detected. A large amount of collagen and osteoid tissues had formed (Figure 2). Immunohistochemical studies showed positive staining for vimentin and were negative for S-100, CD56 and CD34. These pathologic findings are consistent with osteosarcoma. No evidence of an extra-thoracic primary tumor could be obtained through imaging studies. The tumor was therefore diagnosed as a primary osteosarcoma of the mediastinum.

The patient received best supportive care after the operation because of her poor performance status and died 2 months later.

\section{Discussion}

\section{Epidemiology and clinical characteristics}

ESOS is a malignant neoplasm producing osteoid in places other than bones or periosteum. It accounts for approximately $1-2 \%$ of all soft tissue sarcomas and $2-4 \%$ of all osteosarcomas (1). Individuals older than 30 years are the most commonly affected population for ESOS, which is quite different from patients with bone osteosarcoma. The prognosis of patients with ESOS remains poor, with reported 5 -year survival rates varying from $25 \%$ to $66 \%$ (2-4).

Primary intrathoracic ESOS is extremely rare and a total of 60 ESOS cases have been reported in the international literature (Table 1). The majority of cases of thoracic ESOS have presented in the lung $(\mathrm{n}=24,40 \%)$, with 9,14 and 9 cases presenting in the mediastinum, pleura, or chest wall, respectively. Four additional chest ESOS cases did not document specific locations.

The patient characteristics are summarized in Table 1 . The median age of the 60 patients was 60 years (range, $14-93$ years). A majority of the cases involved males (65\%, $39 / 60$ cases), which is similar to previously reported case series (30). The tumors were usually large with a median size of $8.2 \mathrm{~cm}$ (range, $2.5-30 \mathrm{~cm}$ ).

In the cases collected here, some patients had a previous history of radiation exposure, chemotherapy, asbestos exposure, pulmonary tuberculosis or traumatic hemothorax $(2,7,10,11,35,41,47)$. The patient in the case study reported here was previously exposed to aluminum dust. It was speculated that pulmonary inflammation caused by the aforementioned factors might mediate tumorigenesis.

The most common manifestation is respiratory related symptoms caused by compression or invasion of surrounding structures such as cough, dyspnea or chest pain. Some patients were asymptomatic.

\section{Diagnosis}

The intrathoracic ESOS usually grows into a large tumor because initial symptoms are often non-specific. Ossification accompanied by malignant features on the chest CT scan is strongly suggestive of an osteosarcoma although a few exceptions were reported $(38,40)$.

A definitive diagnosis was confirmed histopathologically. ESOS usually has a uniform sarcomatous pattern and produces osteoid. The criteria for the diagnosis of 

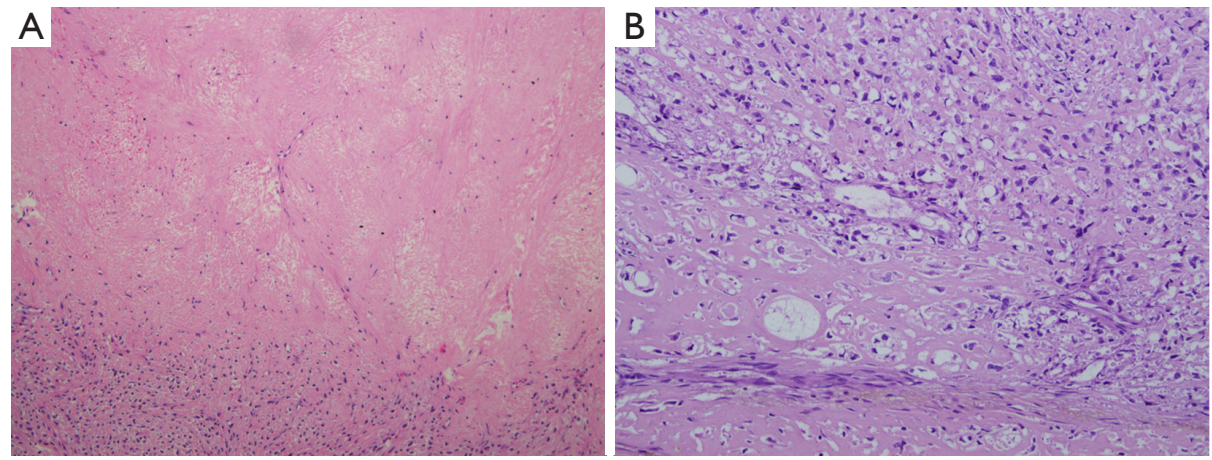

Figure 2 Microscopic findings show malignant cartilaginous foci. H\&E staining. Magnification: $(A) \times 100 ;(B) \times 200$.

primary ESOS are as follows: the presence of a uniform morphological pattern of sarcomatous tissue that excludes the possibility of malignant mesenchymoma, the production of malignant osteoid or bone by the sarcoma and a primary osseous tumor is excluded (51).

The histopathologic features of ESOS are the same as those originating from the skeletal system, including osteoblastic, fibroblastic, and chondroblastic subtypes. Small cell, giant cell, and telangiectatic subtypes occur less often. The immunophenotype of ESOS is also similar to osteosarcoma of the bone. CD99 is expressed in all types of osteosarcoma. ALP staining is positive and osteocalcin is the most specific antigen for ESOS. ESOSs are uniformly positive for vimentin, with some cases expressing smooth muscle actin, desmin, S-100 protein, EMA and keratin (52).

\section{Treatment and prognosis}

The outcome for patients with primary thoracic ESOS remains poor. The majority of patients died within months because of rapid disease progression. The overall 1-, 2and 5 -year survival was merely $41.8 \%, 31.3 \%$ and $22.3 \%$, respectively (Figure $3 A$ ). The median follow-up time was 7 months (range, 1-100 months) and the median overall survival was 11 months (95\% CI: 8.1-13.9).

The median overall survival for ESOS in the mediastinum, lung and other locations was 4.0 (1.3-6.7), 10.0 (5.3-14.7) and $24(10.7-37.3)$ months, respectively. Comparing with ESOS located in the chest wall or pleura, ESOS in the mediastinum and lung had a significantly worse overall survival (log-rank $\mathrm{P}=0.0443$; Figure $3 B$ ).

It is noteworthy that ESOS can be further classified into either low or high-grade. While the majority of published cases had high-grade histological features of marked cellular atypia, extensive areas of necrosis and atypical mitotic figures, Yu et al. reported a case of low-grade mediastinal ESOS characterized by mild cytological atypia. The low-grade ESOS had a slow progression and the patient demonstrated long-term survival after resection (12).

Little is known about the factors affecting the survival of ESOS patients (51). Complete surgical resection is the optimal treatment to improve survival (9). Chemotherapy is also advisable, especially for those without surgical indication (2). In ESOS of the pleura, tumor size was considered as a major predictor of survival (4). Among the 57 cases with documented treatment in this series, $53 \%$ $(n=30)$ had surgery, 26\% $(n=15)$ received chemotherapy and $19 \%(n=11)$ received radiation therapy. The chemotherapy regimens included doxorubicin, cyclophosphamide, cisplatin, or methotrexate $(10,12)$. Univariate and multivariate Cox regression analyses demonstrated that surgical treatment, chemotherapy and radiotherapy were three independent favorable prognostic factors for survival in ESOS patients (Table 2).

Despite complete resection, local recurrence occurred in $22 \%(2 / 9)$ of post-operative cases with well documented follow-up records. In addition, metastases occurred in $66 \%$ (6/9) of post-operative patients. The most common site of metastasis was the lung $(55 \%, 5 / 9)$ and the kidney, brain or adrenal glands were other involved metastatic sites.

\section{Conclusions}

Primary thoracic ESOS is a rare but aggressive tumor associated with a very poor prognosis. Most ESOS cases are asymptomatic in the early stages and difficult to diagnose through small sample biopsies. Physicians should be aware of ESOS as a possibility, especially when 
Table 1 Patient characteristics

\begin{tabular}{|c|c|c|c|c|c|c|c|c|}
\hline Location & Case No. & Age & Sex & Symptom & Size $(\mathrm{cm})$ & Reference & Treatment & Survival (months) \\
\hline \multirow{7}{*}{$\begin{array}{l}\text { Mediastinum } \\
(\mathrm{n}=9)\end{array}$} & 2 & 22 & M & Chest pain, mild dyspnea & 13 & Ikeda [1974] (6) & Surgery, RT & CDF $60+$ months postop \\
\hline & 3 & 30 & M & $\begin{array}{l}\text { Dyspnea on exertion, } \\
\text { fatigue }\end{array}$ & - & Catanese [1988] (7) & & DOD $1 \mathrm{~m}$ after onset \\
\hline & 4 & 69 & $\mathrm{~F}$ & - & 8.5 & Greenwood [1989] (8) & Surgery & - \\
\hline & 6 & 21 & M & Dyspnea & 7 & Ulusakarya [1999] (10) & Surgery, CT & DOD 4 months postop \\
\hline & 7 & 77 & $\mathrm{~F}$ & Shortness of breath & 16 & Hishida [2009] (11) & Surgery & DOD 4 months postop \\
\hline & 8 & 38 & $\mathrm{~F}$ & Cough & 5.5 & Yu [2015] (12) & Surgery, CT & CDF 28+ months postop \\
\hline & 9 & 56 & $\mathrm{~F}$ & Neck mass & 11 & Our case & Surgery & DOD 2 months postop \\
\hline \multirow{18}{*}{ Lung $(n=24)$} & 12 & 66 & M & $\begin{array}{l}\text { Dyspnea, chest pain, } \\
\text { hemoptysis }\end{array}$ & $>10$ & Nosanchuk [1969] (15) & - & DOD 4 months after onset \\
\hline & 13 & 62 & M & Pneumonia & 6 & Reingold [1971] (16) & CT & DOD 7 months after onset \\
\hline & 14 & 56 & $\mathrm{~F}$ & Chills, fever, chest pain & 7 & Reingold [1971] (16) & Surgery & CDF 14 months after onset \\
\hline & 15 & 49 & $\mathrm{~F}$ & - & - & Bagarić [1982] (17) & - & DOD \\
\hline & 16 & 77 & $\mathrm{~F}$ & Asymptomatic & 4 & Nascimento [1982] (18) & Surgery & DUC 6 months postop \\
\hline & 17 & 72 & M & Asymptomatic & 5.5 & Nascimento [1982] (18) & Surgery & DUC 10 months postop \\
\hline & 18 & 81 & M & Dyspnea & $>10$ & Colby [1989] (19) & Surgery & DOC several months later \\
\hline & 23 & 70 & M & Asymptomatic & 6 & Petersen [1990] (21) & Surgery, RT & CDF 6 months after onset \\
\hline & 24 & 59 & M & Influenza-like & 11 & Stark [1990] (22) & Surgery & - \\
\hline & 25 & 58 & M & Fever, cough & 18 & Bhalla [1992] (23) & - & DOD 1 months after onset \\
\hline & 26 & 72 & M & - & - & Miller (1993) (24) & $\mathrm{CT}, \mathrm{RT}$ & DOD 12 months after onset \\
\hline & 27 & 56 & M & Tingling in left fingertips & 4 & Sievert [2000] (25) & Surgery & CDF 12 months postop \\
\hline & 28 & 33 & $\mathrm{~F}$ & Cough, chest pain & 5.5 & Chapman [2001] (26) & Surgery, CT & CDF 42 months postop \\
\hline & 29 & 74 & $\mathrm{~F}$ & Asymptomatic & 5.7 & Magishi [2004] (27) & Surgery & DOD 11 months postop \\
\hline & 30 & 72 & M & Dyspnea & 9 & Kadowaki [2005] (28) & - & DOD 5 months after onset \\
\hline & 31 & 77 & M & $\begin{array}{l}\text { Back pain, limb edema, } \\
\text { hemosputum }\end{array}$ & 11 & Kadowaki [2005] (28) & - & DOD 3 months after onset \\
\hline & 32 & 72 & M & Dyspnea & 30 & Miimi [2008] (29) & - & DOD 7 months after onset \\
\hline & 33 & 58 & $\mathrm{~F}$ & Asymptomatic & 2.5 & Karfis [2010] (30) & $\begin{array}{l}\text { Surgery, CT, } \\
\text { RT }\end{array}$ & CDF 6 months postop \\
\hline
\end{tabular}

Table 1 (continued) 
Table 1 (continued)

\begin{tabular}{|c|c|c|c|c|c|c|c|c|}
\hline Location & Case No. & Age & Sex & Symptom & Size $(\mathrm{cm})$ & Reference & Treatment & Survival (months) \\
\hline \multirow[t]{10}{*}{ Pleural $(n=14$} & & 61 & M & $\begin{array}{l}\text { Chest pain, cough, } \\
\text { hemoptysis, weight loss }\end{array}$ & & Cohn [1968] (31) & Surgery & DOD shortly postop \\
\hline & 36 & 73 & $\mathrm{~F}$ & - & - & Pearson [1969] (32) & Surgery & DOD 6 months postop \\
\hline & 37 & 93 & M & Asymptomatic & 4 & Connolly [1991] (33) & - & DOD 24 months \\
\hline & 39 & 73 & M & Chest pain, hemoptysis & 4.5 & Sabloff [2003] (35) & Surgery & - \\
\hline & 40 & 76 & M & Breathlessness & - & Chandak [2007] (36) & Biopsy & - \\
\hline & 41 & 74 & M & Cough, breathless & 11.3 & Matono [2008] (37) & - & - \\
\hline & 42 & 64 & M & cough & 13.1 & Kasagi [2009] (38) & Surgery, RT & - \\
\hline & 45 & 67 & M & $\begin{array}{l}\text { Dyspnea on exertion, } \\
\text { cough }\end{array}$ & 12 & Shiota [2013] (41) & Surgery, CT & DOD 24 months postop \\
\hline & 46 & 37 & $\mathrm{~F}$ & Flank pain, dyspnea & 8 & Lee [2014] (42) & Surgery, CT & CDF 14 months postop \\
\hline & 47 & 75 & $\mathrm{~F}$ & Chest pain, hemoptysis & 8.2 & Rapicetta [2017] (43) & - & - \\
\hline \multirow[t]{6}{*}{$\begin{array}{l}\text { Chest wall } \\
(n=9)\end{array}$} & 48 & 14 & $\mathrm{~F}$ & $\begin{array}{l}\text { Back pain, cough, } \\
\text { dyspnea }\end{array}$ & - & Stauss [1951] (44) & - & DOD 7 months \\
\hline & 49 & 59 & M & - & - & Hoffmann [1966] (45) & Surgery & - \\
\hline & 50 & 53 & $\mathrm{~F}$ & - & - & Das Gupta [1968] (46) & Surgery & DOD 46 months postop \\
\hline & 51 & 41 & $\mathrm{~F}$ & Lump & 3 & Alpert [1973] (47) & $\begin{array}{l}\text { Excisional } \\
\text { biopsy }\end{array}$ & CDF 12 months after onset \\
\hline & 55 & 76 & M & - & - & Nystrom [2016] (50) & Surgery & DOD 9 months \\
\hline & 56 & 58 & M & - & 17 & Nystrom [2016] (50) & $\mathrm{CT}, \mathrm{RT}$ & DOD 12 months \\
\hline \multirow{4}{*}{$\begin{array}{l}\text { Chest (not } \\
\text { specified) } \\
(\mathrm{n}=4)\end{array}$} & 57 & 47 & M & - & - & Torigoe [2007] (2) & CT & DOD 28 months \\
\hline & 58 & 25 & M & - & - & Torigoe [2007] (2) & CT & CDF 70 months \\
\hline & 59 & 39 & M & - & - & Torigoe [2007] (2) & $\mathrm{CT}, \mathrm{RT}$ & CDF 68 months \\
\hline & 60 & 76 & M & - & - & Torigoe [2007] (2) & $\mathrm{RT}$ & DOD 6 months \\
\hline
\end{tabular}

$\mathrm{CT}$, chemotherapy; RT, radiotherapy; DOD, dead of disease; CDF, continuous disease-free; DOC, dead of other causes; DUC, dead of unknown causes. 

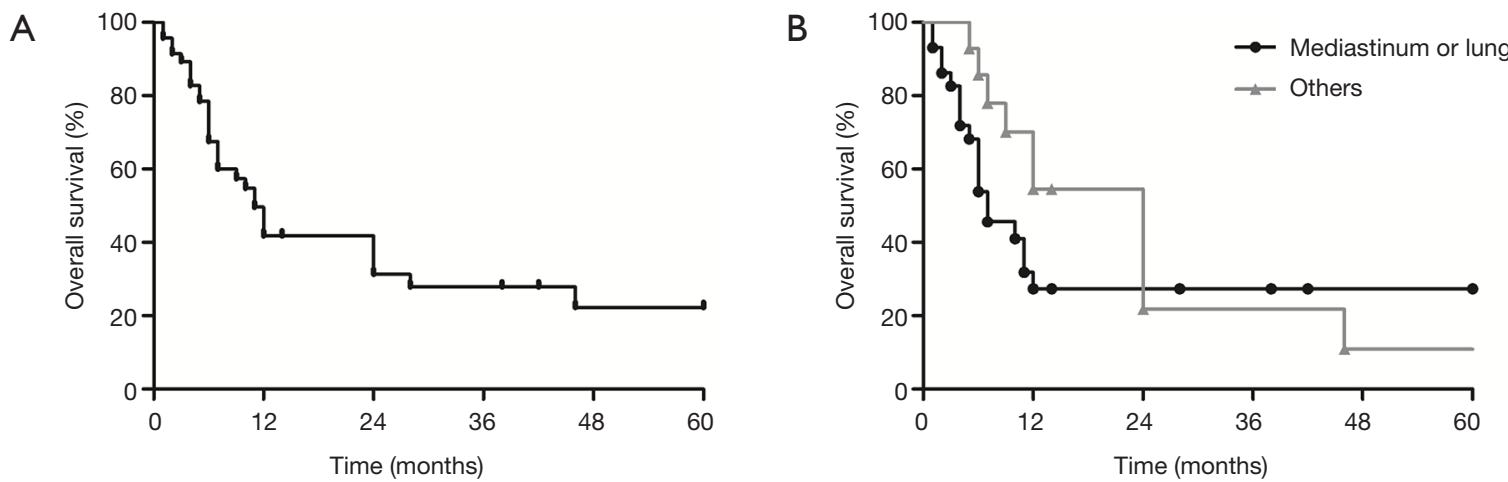

Figure 3 (A) Overall survival of all 60 cases of intrathoracic ESOS; (B) survival curves of ESOS patients with different originating sites. The median overall survival for patients with intrathoracic ESOS was 11 months (95\% CI: 8.1-13.9) and the 5-year overall survival was $22.3 \%$. ESOS in the mediastinum and lung had a significantly worse overall survival compared with that located in the chest wall or pleural (log-rank $\mathrm{P}=0.0443)$.

Table 2 Univariate and multivariate analysis of prognostic factors of survival

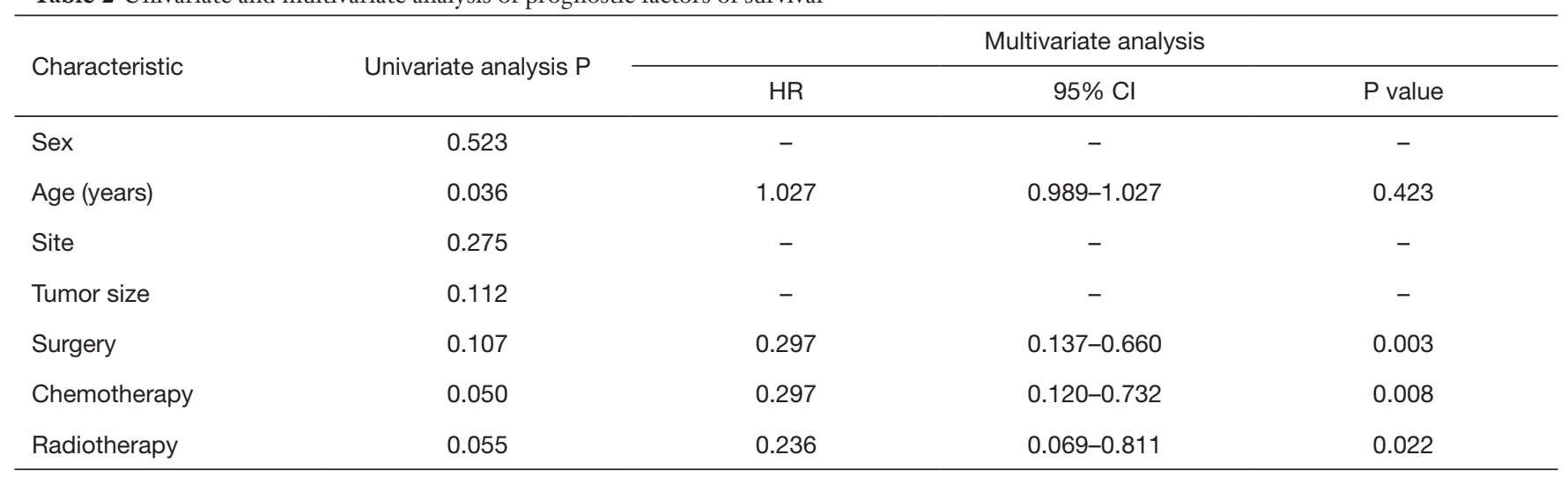

Indicators with $\mathrm{P}$ value less than 0.2 by univariate analysis were included in the multivariate analysis.

calcification is present in CT images. Histologically, osteoid and bone production is a typical characteristic of ESOS and immunohistochemistry serves as a diagnostic aid. If considered as a primary tumor, surgical resection is the primary choice and chemotherapy and radiotherapy are considered as effective.

\section{Acknowledgements}

None.

\section{Footnotes}

Conflicts of Interest: The authors have no conflicts of interest to declare.
Informed Consent: Written informed consent was obtained from the patient for publication of this manuscript and any accompanying images.

\section{References}

1. Rosenberg AE HS. Extraskeletal osteosarcoma. In Fletcher CD, Unni KK, Mertens F, editors, Pathology and Genetics of Tumours of Soft Tissue and Bone. Lyon: IARC press, 2002;182-3.

2. Torigoe T, Yazawa Y, Takagi T, et al. Extraskeletal osteosarcoma in Japan: multiinstitutional study of 20 patients from the Japanese Musculoskeletal Oncology Group. J Orthop Sci 2007;12:424-9.

3. Lee JS, Fetsch JF, Wasdhal DA, et al. A review of 
40 patients with extraskeletal osteosarcoma. Cancer 1995;76:2253-9.

4. Bane BL, Evans HL, Ro JY, et al. Extraskeletal osteosarcoma. A clinicopathologic review of 26 cases. Cancer 1990;65:2762-70.

5. Wilson H. Extraskeletal ossifying tumors. Ann Surg 1941;113:95-112.

6. Ikeda T, Ishihara T, Yoshimatsu H, et al. Primary osteogenic sarcoma of the mediastinum. Thorax 1974;29:582-8.

7. Catanese J, Dutcher JP, Dorfman HD, et al. Mediastinal osteosarcoma with extension to lungs in a patient treated for Hodgkin's disease. Cancer 1988;62:2252-7.

8. Greenwood SM, Meschter SC. Extraskeletal osteogenic sarcoma of the mediastinum. Arch Pathol Lab Med 1989;113:430-3.

9. Burt M, Ihde JK, Hajdu SI, et al. Primary sarcomas of the mediastinum: results of therapy. J Thorac Cardiovasc Surg 1998;115:671-80.

10. Ulusakarya A, Terrier P, Regnard JF, et al. Extraskeletal osteosarcoma of the mediastinum after treatment of a mediastinal germ-cell tumor. Am J Clin Oncol 1999;22:609-14.

11. Hishida T, Yoshida J, Nishimura M, et al. Extraskeletal osteosarcoma arising in anterior mediastinum: brief report with a review of the literature. J Thorac Oncol 2009;4:927-9.

12. Yu H, Wu Z, Cui Y, et al. Low-grade extraskeletal osteosarcoma of the mediastinum: report of a case and review of literature. Int J Clin Exp Pathol 2015;8:3279-81.

13. Greenspan EB. Primary osteoid chondrosarcoma of the lung: report of a case. Am J Cancer 1933;18:603-9.

14. Yamashita T, Kiyota T, Ukishima G, et al. Autopsy case of chondro-osteoidsarcoma originating in the lung. Showa Igakkai Zasshi 1964;23:472-3.

15. Nosanchuk JS, Weatherbee L. Primary osteogenic sarcoma in lung. Report of a case. J Thorac Cardiovasc Surg 1969;58:242-7.

16. Reingold IM, Amromin GD. Extraosseous osteosarcoma of the lung. Cancer 1971;28:491-8.

17. Bagarić I, Belicza M. Extraskeletal osteogenic sarcoma of the lungs. Lijec Vjesn 1982;104:467-70.

18. Nascimento AG, Unni KK, Bernatz PE. Sarcomas of the lung. Mayo Clin Proc 1982;57:355-9.

19. Colby TV, Bilbao JE, Battifora H, et al. Primary osteosarcoma of the lung. A reappraisal following immunohistologic study. Arch Pathol Lab Med 1989;113:1147-50.
20. Loose JH, el-Naggar AK, Ro JY, et al. Primary osteosarcoma of the lung. Report of two cases and review of the literature. J Thorac Cardiovasc Surg 1990;100:867-73.

21. Petersen M. Radionuclide detection of primary pulmonary osteogenic sarcoma: a case report and review of the literature. J Nucl Med 1990;31:1110-4.

22. Stark P, Smith DC, Watkins GE, et al. Primary intrathoracic extraosseous osteogenic sarcoma: report of three cases. Radiology 1990;174:725-6.

23. Bhalla M, Thompson BG, Harley RA, et al. Primary extraosseous pulmonary osteogenic sarcoma: CT findings. J Comput Assist Tomogr 1992;16:974-6.

24. Miller DL, Allen MS. Rare pulmonary neoplasms. Mayo Clin Proc 1993;68:492-8.

25. Sievert LJ, Elwing TJ, Evans ML. Primary pulmonary osteogenic sarcoma. Skeletal Radiol 2000;29:283-5.

26. Chapman AD, Pritchard SC, Yap WW, et al. Primary pulmonary osteosarcoma: case report and molecular analysis. Cancer 2001;91:779-84.

27. Magishi K, Yoshida H, Izumi Y, et al. Primary osteosarcoma of the lung: report of a case. Surg Today 2004;34:150-2.

28. Kadowaki T, Hamada H, Yokoyama A, et al. Two cases of primary pulmonary osteosarcoma. Intern Med 2005;44:632-7.

29. Niimi R, Matsumine A, Kusuzaki K, et al. Primary osteosarcoma of the lung: a case report and review of the literature. Med Oncol 2008;25:251-5.

30. Karfis EA, Karaiskos T, Cheva A, et al. Primary extraosseous osteosarcoma of the lung. Acta Oncol 2010;49:114-6.

31. Cohn L, Hall AD. Extraosseous osteogenic sarcoma of the pleura. Ann Thorac Surg 1968;5:545-9.

32. Pearson KD, Rubin D, Szemes GC, et al. Extraosseous osteogenic sarcoma of the chest. Br J Dis Chest 1969;63:231-4.

33. Connolly JP, McGuyer CA, Sageman WS, et al. Intrathoracic osteosarcoma diagnosed by CT scan and pleural biopsy. Chest 1991;100:265-7.

34. Meeus I, Galdermans D, Roland J, et al. Spectacular bone scintigraphy and transverse SPECT images in primary osteosarcoma of the pleura. Clin Nucl Med 1994;19:738-40.

35. Sabloff B, Munden RF, Melhem AI, et al. Radiologicpathologic conferences of the University of Texas M. D. Anderson Cancer Center: Extraskeletal osteosarcoma of the pleura. AJR Am J Roentgenol 2003;180:972.

36. Chandak P, Hunt I, Rawlins R, et al. Bone or pleura? Primary pleural osteosarcoma. J Thorac Cardiovasc Surg 
2007;133:587-8.

37. Matono R, Maruyama R, Ide S, et al. Extraskeletal osteosarcoma of the pleura: a case report. Gen Thorac Cardiovasc Surg 2008;56:180-2.

38. Kasagi Y, Yamazaki K, Nakashima A, et al. Chondroblastic osteosarcoma arising from the pleura: report of a case. Surg Today 2009;39:1064-7.

39. Wang W, Quan CB, Li N, et al. Diagnosis of pleural cavity extraskeletal osteosarcoma: a case report and literature review. Zhonghua Jie He He Hu Xi Za Zhi 2010;33:202-5.

40. Tokue H, Tsushima Y, Endo K. Computed tomography findings of the progress of calcification in extraskeletal osteosarcoma without calcification derived from the pleura. Gen Thorac Cardiovasc Surg 2011;59:447-50.

41. Shiota H, Yasukawa T, Hirai A, et al. Extraskeletal osteosarcoma of the pleura:report of a case. Ann Thorac Cardiovasc Surg 2013;19:297-301.

42. Lee CH, Park CR, Kim JW, et al. Extraskeletal osteosarcoma arising from the pleura. Korean J Thorac Cardiovasc Surg 2014;47:320-4.

43. Rapicetta C, Lococo F, Carlinfante G, et al. Extraskeletal Osteosarcoma Arising from the Pleura. Lung 2017;195:523-5.

44. Stauss HK. Osteogenic sarcoma arising in traumatic hemothorax and hematoma of the thoracic wall. Surgery

Cite this article as: Qian J, Zhang XY, Gu P, Shao JC, Han BH, Wang HM. Primary thoracic extraskeletal osteosarcoma: a case report and literature review. J Thorac Dis 2017;9(12):E1088-E1095. doi: 10.21037/jtd.2017.11.111
1951;29:917-28.

45. Hoffmann K, Fine G, Ponka JL, et al. Extraskeletal osteogenic sarcoma--case report. Henry Ford Hosp Med J 1966;14:381-6.

46. Das Gupta TK, Hajdu SI, Foote FW Jr. Extraosseous osteogenic sarcoma. Ann Surg 1968;168:1011-22.

47. Alpert LI, Abaci IF, Werthamer S. Radiation-induced extraskeletal osteosarcoma. Cancer 1973;31:1359-63.

48. Kelkar G, Moiyadi AV, Kane SV. Extraskeletal osteosarcoma of the chest-wall with delayed metastasis to the sphenoid. Indian J Cancer 2010;47:82-4.

49. Sabatier R, Bouvier C, de Pinieux G, et al. Low-grade extraskeletal osteosarcoma of the chest wall: case report and review of literature. BMC Cancer 2010;10:645.

50. Nystrom LM, Reimer NB, Reith JD, et al. The Treatment and Outcomes of Extraskeletal Osteosarcoma: Institutional Experience and Review of The Literature. Iowa Orthop J 2016;36:98-103.

51. Allan CJ, Soule EH. Osteogenic sarcoma of the somatic soft tissues. Clinicopathologic study of 26 cases and review of literature. Cancer 1971;27:1121-33.

52. Mavrogenis, AF, Papagelopoulos PJ. Soft Tissue Tumors: Extraskeletal osteosarcoma. Atlas Genet Cytogenet Oncol Haematol 2014;18:443-6. 